\title{
Analisis Sistem Proteksi Kebakaran Gedung Laboratorium Teknik Mesin Fakultas Teknik Universitas Riau
}

\author{
Muhammad Reza ${ }^{1}$, Aryo Sasmita $^{2}$, Ery Laksono Sadewo $^{3}$ \\ 1,2,3 Teknik Lingkungan, Universitas Riau \\ ${ }^{1}$ zha6290@gmail.com \\ *Corresponding author - Email : zha6290@gmail.com
}

Artkel Info - : Received : 30 Jan 2020; Revised : 20 Feb 2020; Accepted: 28 Feb 2020

\begin{abstract}
Abstrak
Sistem proteksi kebakaran digunakan untuk mendeteksi dan memadamkan kebakaran sedini mungkin dengan menggunakan peralatan yang digerakkan secara manual dan otomatis. Laboratorium Teknik Mesin Fakultas Teknik Universtias Riau merupakan salah satu bangunan yang memiliki potensi akan terjadinya kebakaran, jika tidak memiliki sistem proteksi kebakaran yang memadai. Laboratorium tersebut memiliki mesin-mesin yang jika tidak dikelola dengan baik akan menjadi pemicu terjadinya kebakaran. Menurut Badan Litbang Pekerjaan Umum, 2005 tentang Pemeriksaan Keselamatan Kebakaran Gedung, setiap gedung memiliki 4 komponen utilitas, yaitu Kelengkapan Tapak, Sarana Penyelamatan, Sistem Proteksi Aktif, dan Sistem Proteksi Pasif. Pengumpulan data dilakukan dengan melakukan survei kondisi eksisting dan mencari data kepada kelembagaan atau instansi terkait. Penelitian ini bertujuan untuk mengetahui sejauh mana penerapan Sistem Proteksi Kebakaran di Fakultas Teknik Universitas Riau. Metode yang digunakan dalam penelitian ini adalah metode deskriptif kuantitatif dengan desain studi kasus, hasil penelitian yang kemudian diolah dan dianalisis untuk diambil kesimpulannya. Penilaian kondisi keseluruhan sistem proteksi kebakaran Laboratorium Teknik Mesin Fakultas Teknik Universitas Riau yaitu sebesar 72.5\%. Menurut Pemeriksaan Keselamatan Kebakaran Bangunan Gedung tahun 2005 menunjukan bahwa kondisi sistem proteksi kebakaran pada bangunan Laboratorium Teknik Mesin Fakultas Teknik Universitas Riau dalam kondisi cukup. Dengan kondisi yang ada ini diharapkan sistem proteksi dapat berfungsi dengan baik saat dibutuhkan bila sewaktu-waktu terjadi bahaya kebakaran.

Kata Kunci : sistem proteksi, kebakaran, laboratorium,
\end{abstract}

\section{Abstract}

Fire protection systems are used to detect and extinguish fires as early as possible by using equipment that is moved manually and automatically. Laboratory of Mechanical Engineering, Faculty of Engineering, Universtias Riau is one of the buildings that has the potential for a fire, if it does not have an adequate fire protection system. The laboratory has machines which if not managed properly will trigger a fire. According to the Public Works Research and Development Agency, 2005 on Building Fire Safety Inspections, each building has 4 utility components, namely Site Completeness, Rescue Facilities, Active Protection Systems, and Passive Protection Systems. Data collection is carried out by surveying existing conditions and looking for data to related institutions or institutions. This study aims to determine the extent of the application of the Fire Protection System at the Faculty of Engineering, University of Riau. The method used in this research is quantitative descriptive method with case study design, the results of the study are then processed and analyzed to draw conclusions. The overall condition assessment of the fire protection system of the Mechanical Engineering Laboratory, Faculty of Engineering, University of Riau is $72.5 \%$. According to the Fire Safety Examination of Buildings in 2005, the condition of the fire protection system in the Mechanical Engineering Laboratory Laboratory of Riau University was sufficient. With these conditions it is expected that the protection system can function properly when needed if at any time a fire hazard occurs.

Keywords: protection system, fire, laboratory 


\section{PENDAHULUAN}

Sistem proteksi kebakaran pada bangunan gedung dan lingkungan menurut Peraturan Menteri Pekerjaan Umum No. 26/PRT/M/2008 tentang Persyaratan Teknis Sistem Proteksi Kebakaran pada Bangunan Gedung dan Lingkungan adalah sistem yang terdiri atas peralatan, kelengkapan dan sarana, yang terpasang pada bangunan yang digunakan baik untuk tujuan sistem proteksi aktif, sistem proteksi pasif, maupun cara - cara pengelolaan dalam rangka melindungi bangunan dan lingkungannya terhadap bahaya kebakaran. Sistem proteksi kebakaran digunakan untuk mendeteksi dan memadamkan kebakaran sedini mungkin dengan menggunakan peralatan yang digerakkan secara manual dan otomatis.

Kebakaran disebabkan oleh berbagai faktor, namun secara umum faktor-faktor yang menyebabkan kebakaran yaitu faktor manusia dan faktor teknis (Ramli, 2010). Untuk kasus kebakaran di indonesia sekitar $62,8 \%$ disebabkan oleh listrik atau adanya hubungan pendek arus listrik. Penataan ruang dan minimnya prasarana penanggulangan bencana kebakaran juga berkontribusi terhadap timbulnya kebakaran, khususnya kebakaran industri dan pemukiman (Nugroho, 2010 dikutip dalam Kurniawan, 2014).

Pada umumnya, unit pemadam kebakaran tiba dilokasi setelah kebakaran semakin meluas, beberapa faktornya dikarenakan lokasi susah dijangkau, macet atau jarak unit pemadam yang jauh dari lokasi kebakaran, maka dari itu diperlukan solusi untuk mengatasinya sehingga kerugian yang ditimbulkan dapat diminimalisir (Rizki dkk, 2017).

Universitas Riau merupakan salah satu instansi pendidikan yang ada di Provinsi Riau yang memiliki beberapa Fakultas di antaranya adalah Fakultas Teknik. Gedung Fakultas Teknik Universitas Riau memiliki luas bangunan $8.915 \mathrm{~m} 2$ terdiri dari Gedung $\mathrm{C}$ yang didalamnya terdapat ruang perkuliahan, ruang dosen, ruang staf Fakultas Teknik, ruang perpustakaan, photocopy center, ruang rapat, serta bangunan lain seperti Laboratorium/studio/bengkel, dan Mushola. Bangunan gedung Fakultas Teknik Universitas Riau ini banyak faktor-faktor yang dapat menyebabkan terjadinya bahaya kebakaran, diantaranya adalah peralatan elektronik, dan instalasi listrik disetiap ruang gedung yang apabila tidak di kelola dengan baik dapat menyebabkan kebakaran dan adanya buku-buku di perpustakaan, arsip-arsip dosen, kain, bahan kimia yang berada di laboratorium dapat menambah kobaran api menjadi lebih besar apabila terjadi kebakaran.

Laboratorium Teknik Mesin Fakultas Teknik Universtias Riau merupakan salah satu bangunan yang memiliki potensi akan terjadinya kebakaran, jika tidak memiliki sistem proteksi kebakaran yang memadai. Laboratorium tersebut memiliki mesinmesin yang jika tidak dikelola dengan baik akan menjadi pemicu terjadinya kebakaran.

Penelitian ini bertujuan untuk mengetahui sejauh mana penerapan Sistem Proteksi Kebakaran di Fakultas Teknik Universitas Riau. Metode yang digunakan dalam penelitian ini adalah metode deskriptif kuantitatif dengan desain studi kasus, hasil penelitian yang kemudian diolah dan dianalisis untuk diambil kesimpulannya.

Menurut Badan Litbang Pekerjaan Umum, 2005 Tentang Pemeriksaan Keselamatan Kebakaran Gedung, setiap gedung memiliki 4 komponen utilitas. Kelengkapan Tapak, Sarana Penyelamatan, Sistem Proteksi Aktif, dan Sistem Proteksi Pasif.

\section{METODOLOGI}

Pengumpulan data dilakukan dengan melakukan survei kondisi eksisting dan mencari data kepada kelembagaan atau instansi terkait.

\subsection{Check list pengamatan di lapangan}


Lembar Check list merupakan lembar yang di persiapkan yang fungsinya untuk mengetahui apakah komponen-komponen sistem proteksi kebakaran di suatu bangunan sudah terpasang dengan baik. Lembar check list pada penelitian ini mengacu pada Badan Litbang Pekerjaan Umum tahun 2005 tentang pemeriksaan keselamatan kebakaran bangunan gedung.

\subsection{Skala likert}

Setelah di dapatkan hasil dari data check list dilapangan tahap selanjutnya ialah melakukan penilaian terhadap masingmasing komponen sistem tanggap darurat menggunakan skala likert. Setelah semua komponen dinilai perhitungan selanjutnya adalah dicari nilai rata-rata dan nilai persentase kesesuaian.

\subsection{Tingkat penilaian audit kebakaran}

Dari data check list dilapangan dapat di ketahui Kondisi setiap komponen atau bagian bangunan harus dinilai atau dievaluasi. Nilai kondisi komponen proteksi kebakaran bangunan dibagi dalam tiga tingkat, yaitu: BAIK="B" ; SEDANG atau CUKUP $=$ " $\mathrm{C}$ " dan KURANG $=$ " $\mathrm{K}$ " (Ekuivalensi nilai B adalah 100, C adalah 80 dan K adalah 60). Penilaian didasarkan pada kriteria atau pembatasan kondisi komponen bangunan.

\subsection{Pembobotan parameter komponen sistem keselamatan bangunan.}

Untuk tahapan pembobotan harus dilakukan pada setiap masing-masing komponen sistem proteksi kebakaran. Nilai pembobotan mengacu kepada Peraturan Badan Litbang Pekerjaan Umum, 2005 Tentang Pemeriksaan Keselamatan Kebakaran Bangunan Gedung.

Cara Pengisian dan Pengolahan Data

Hasil pemeriksaan dan pencatatan kondisi nyata komponen utilitas digunakan untuk proses pengolahan dan penentuan nilai keandalan utilitas.
Tabel 2.1 Penilaian Komponen Keselamatan

\begin{tabular}{cccccc}
\multicolumn{6}{c}{ Bangunan } \\
\hline No. & Variabel & $\begin{array}{c}\text { Hasil } \\
\text { Penilaian }\end{array}$ & $\begin{array}{c}\text { Standar } \\
\text { Penilaian }\end{array}$ & Bobot & $\begin{array}{c}\text { Nilai } \\
\text { Kondisi }\end{array}$ \\
\hline 1 & 2 & 3 & 4 & 5 & 6 \\
\hline \hline
\end{tabular}

Kolom 1, berisi nomor penilaian. Kolom 2, berisi variabel komponen keselamatan bangunan. Kolom 3, menuliskan hasil penilaian. Berdasarkan pengamatan langsung. Penilaian berupa di sajikan dalam bentuk huruf B,C, atau K. Kolom 4, menuliskan penulisan dari kolom 3 yang disajikan dalam bentuk Angka. Kolom 5, menuliskan bobot KSKB (Komponen Sistem Keselamatan Bangunan) tiap komponen dan untuk nilai bobot Sub KSKB. Kolom 6, menuliskan nilai kondisi dengan persamaan :

Nilai kondisi $=$ Hasil Penilaian $\mathrm{x}$ (Sub $\mathrm{KSKB} / 100) \times(\mathrm{KSKB} / 100)$

Setelah keseluruhan komponen di hitung, perhitungan selanjutnya adalah mencari nilai rata-rata dan persentase kesesuaian. Setelah didapatkan hasil dari masingmasing penilaian sistem proteksi kebakaran tahap selanjutnya adalah menghitung hasil penilaian sebagai berikut:

Tabel 2.2 Rekapitulasi Hasil Penilaian Komponen Sistem Proteksi Kebakaran

\begin{tabular}{cccc}
\hline No. & Komponen & $\begin{array}{c}\text { Bobot } \\
(\boldsymbol{\%})\end{array}$ & $\begin{array}{c}\text { Hasil Penilaian } \\
(\boldsymbol{\%})\end{array}$ \\
\hline 1 & 2 & 3 & 4 \\
\hline \hline
\end{tabular}

1. Kolom 1, berisi nomor penilaian

2. Kolom 2, berisi komponen Sistem Proteksi kebakaran

3. Kolom 3, berisi bobot KSKB

4. Kolom 4, berisi nilai hasil penilaian

\section{HASIL DAN PEMBAHASAN}

\subsection{Kelengkapan Teknik Mesin \\ Laboratorium}

Kriteria penilaian komponen kelengkapan 
tapak berdasarkan Badan Litbang Pekerjaan Umum, 2005 tebagi menjadi 4 SUB KSKB dan berikut adalah kesimpulan dari hasil penilaian Kelengkapan Tapak seluruh bangunan Fakultas Teknik Universitas Riau dapat dilihat pada tabel 3.1.

Tabel 3.1 Hasil Penilaian Kelengkapan Tapak Keseluruhan Bangunan Fakultas Teknik

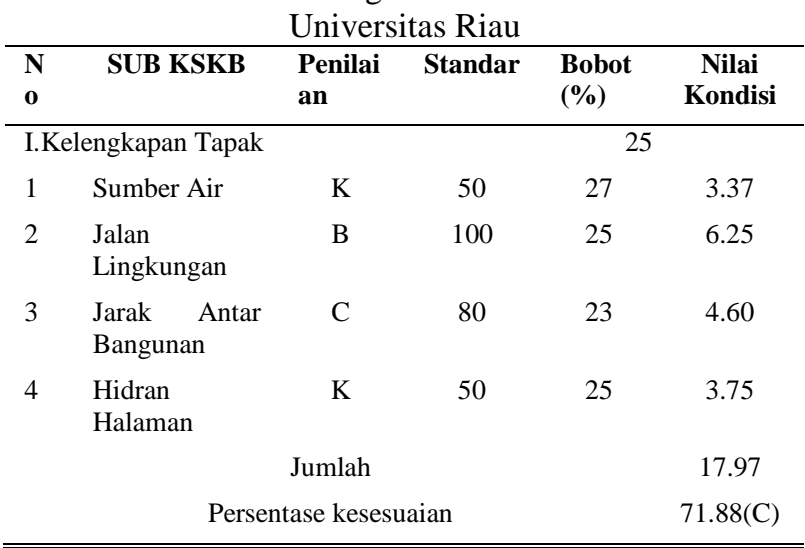

Contoh Perhitungan :

Nilai kondisi sub KSKB Sumber Air $=50 \times(27 / 100) \times(25 / 100)=3.37$

Nilai kondisi sub KSKB Jalan Lingkungan $=100 \times(25 / 100) \times(25 / 100)=6.25$

Nilai kondisi sub KSKB Jarak Antar Bangunan $=80 \times(23 / 100) \times(25 / 100)=$ 4,60

Nilai kondisi sub KSKB Hidran Halaman $=50 \times(25 / 100) \times(25 / 100)=3.75$

Total nilai kondisi komponen kelengkapan tapak sebesar 17.97 dari nilai maksimal komponen kelengkapan tapak sebesar 25. Persentase kesesuaian $=(17.97 / 25) \mathrm{x} 100 \%$ $=71.88(\mathrm{C})$

Berdasarkan tabel 3.1, diperoleh penilaian kondisi kelengkapan tapak untuk keseluruhan bangunan Fakultas Teknik Universitas Riau sebesar $71.88 \%$ atau kondisi kelengkapan tapak secara umum dalam kondisi cukup.

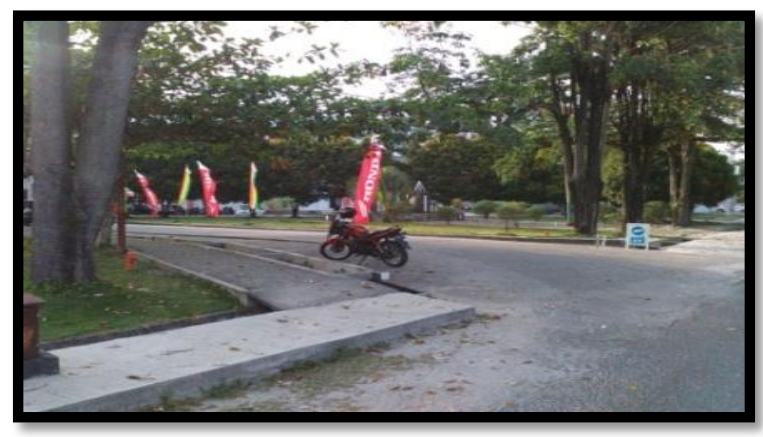

Gambar 3.1 Jalan Lingkungan Pertama

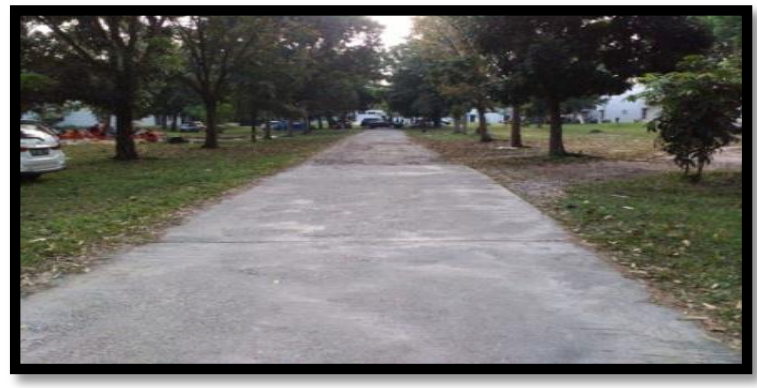

Gambar 3.2 Jalan Lingkungan kedua

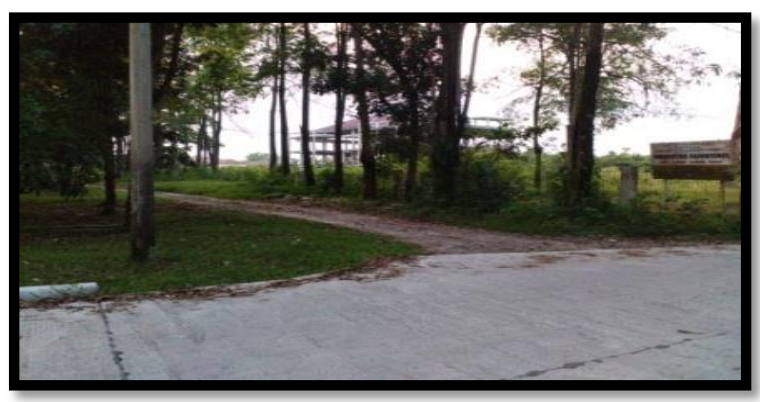

Gambar 3.3 Jalan Lingkungan ketiga

\subsection{Sarana Penyelamatan \\ Laboratorium Teknik Mesin}

Kriteria penilaian komponen sarana penyelamatan berdasarkan Badan Litbang Pekerjaan Umum, 2005 terbagi menjadi 2 SUB KSKB dan berikut adalah kesimpulan dari hasil penilaian Sarana Penyelamatan Laboratorium Teknik Mesin Fakultas Teknik Universitas Riau dapat dilihat pada tabel 3.2. 
Tabel 3.2 Hasil Penilaian Sarana Penyelamatan

Laboratorium Teknik Mesin Fakultas Teknik Universitas Riau

\begin{tabular}{lccccc}
\hline No & SUB KSKB & Penilaian & Standar & $\begin{array}{c}\text { Bobot } \\
(\%)\end{array}$ & $\begin{array}{c}\text { Nilai } \\
\text { Kondisi }\end{array}$ \\
\hline \multicolumn{2}{ll}{ II.Sarana Penyelamatan25 } & & & & \\
1 & Jalan Keluar & B & 100 & 27 & 9.50 \\
2 & Konstruksi & B & 100 & 25 & 8.75 \\
& Jalan Keluar & & & & 18.25 \\
& Jumlah & & $73.00(\mathrm{C})$ \\
\hline
\end{tabular}

Berdasarkan tabel 3.2, diperoleh penilaian kondisi Sarana Penyelamatan untuk bangunan Laboratorium Teknik Mesin Fakultas Teknik Uiversitas Riau sebesar $73.00 \%$. Hal ini berarti kondisi Sarana Penyelamatan pada Laboratorium Teknik Mesin Fakultas Teknik Universitas Riau dalam kondisi cukup.

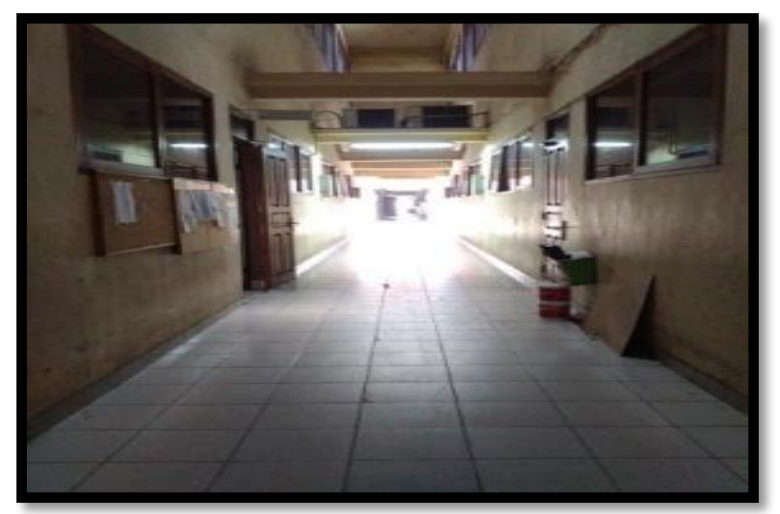

Gambar 3.4 Koridor Laboratorium Teknik Mesin

\subsection{Sistem Proteksi Aktif Laboratorium TeknikMesin}

Kriteria penilaian komponen Sistem Proteksi Aktif berdasarkan Badan Litbang Pekerjaan Umum, 2005 terbagi menjadi 13 SUB KSKB dan berikut adalah kesimpulan dari hasil penilaian Sistem Proteksi Aktif Laboratorium Teknik Mesin Fakultas Teknik Universitas Riau dapat dilihat pada tabel 3.3.

\begin{tabular}{llcccc}
\hline $\begin{array}{c}\text { N } \\
\text { o }\end{array}$ & SUB KSKB & Penilaian & Standar & $\begin{array}{c}\text { Bobot } \\
(\%)\end{array}$ & $\begin{array}{c}\text { Nilai } \\
\text { Kondisi }\end{array}$ \\
\hline $\begin{array}{l}\text { III.Sistem Proteksi Aktif24 } \\
1\end{array}$ & $\begin{array}{l}\text { Deteksi } \\
\text { Alarm }\end{array}$ & $\mathrm{K}$ & 50 & 8 & 1.15 \\
2 & $\begin{array}{l}\text { Siemes } \\
\text { connection }\end{array}$ & $\mathrm{K}$ & 50 & 8 & 1.15 \\
3 & $\begin{array}{l}\text { Pemadam Api } \\
\text { Ringan } \\
\text { (APAR) }\end{array}$ & $\mathrm{C}$ & 80 & 8 & 1.53 \\
4 & Hidran & $\mathrm{K}$ & 50 & 7 & 1.008
\end{tabular}

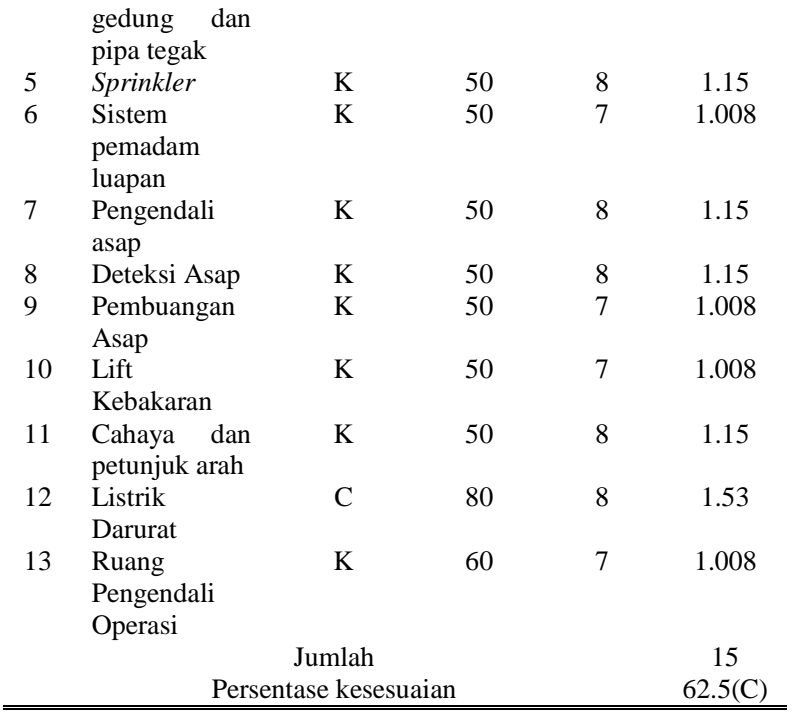

Berdasarkan tabel 3.3, diperoleh penilaian kondisi Sistem Proteksi Aktif untuk bangunan Laboratorium Teknik Mesin Fakultas Teknik Universitas Riau sebesar $62.5 \%$. Hal ini berarti kondisi Sistem Proteksi Aktif pada Laboratorium Teknik Mesin Fakultas Teknik Universitas Riau dalam kondisi cukup.

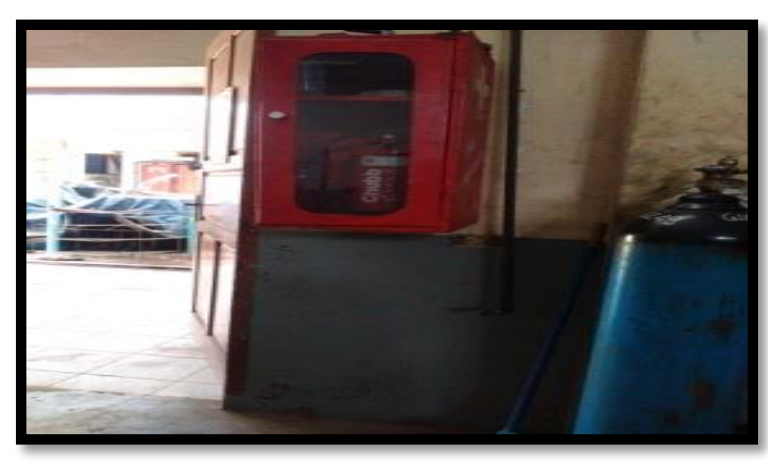

Gambar 3.5 Kondisi eksisting APAR Laboratorium Teknik Mesin

\subsection{Sarana Proteksi Pasif Laboratorium Teknik Mesin}

Kriteria penilaian komponen sarana penyelamatan berdasarkan Badan Litbang Pekerjaan Umum, 2005 tebagi menjadi 2 SUB KSKB dan berikut adalah kesimpulan dari hasil penilaian Sarana Proteksi Pasif seluruh bangunan Fakultas Teknik Universitas Riau dapat dilihat pada tabel 3.4 . 
Tabel 3.4 Hasil Penilaian Sistem Proteksi Pasif Seluruh Bangunan Fakultas Teknik Universitas

\begin{tabular}{|c|c|c|c|c|c|}
\hline \multicolumn{6}{|c|}{ Riau } \\
\hline $\begin{array}{l}\mathbf{N} \\
\mathbf{0}\end{array}$ & SUB KSKB & Penilaian & Standar & $\begin{array}{c}\text { Bobot } \\
(\%)\end{array}$ & $\begin{array}{c}\text { Nilai } \\
\text { Kondisi }\end{array}$ \\
\hline \multicolumn{6}{|c|}{ IV.Sistem Proteksi Pasif24 } \\
\hline 1 & $\begin{array}{l}\text { Ketahanan api } \\
\text { dan struktur } \\
\text { bangunan }\end{array}$ & B & 100 & 36 & 9.36 \\
\hline 2 & $\begin{array}{l}\text { Kompartemenis } \\
\text { asi ruangan }\end{array}$ & B & 100 & 32 & 6.93 \\
\hline 3 & $\begin{array}{l}\text { Perlindungan } \\
\text { bukaan }\end{array}$ & $\mathrm{C}$ & 80 & 32 & 4.99 \\
\hline \multicolumn{5}{|c|}{ Jumlah } & \\
\hline \multicolumn{5}{|c|}{ Persentase kesesuaian } & $81.84(\mathrm{~B})$ \\
\hline
\end{tabular}

Berdasarkan tabel 3.4, diperoleh penilaian kondisi Sistem Proteksi Pasif untuk seluruh bangunan Fakultas Teknik Universitas Riau sebesar $81.84 \%$. Hal ini berarti kondisi Sistem Proteksi Pasif pada seluruh bangunan Fakultas Teknik Universitas Riau dalam kondisi baik.

\section{KESIMPULAN}

Berdasarkan hasil dari pehitungan nilai keandalan untuk masing-masing komponen Sistem Proteksi dapat disimpulkan Hasil Penilaian Sistem Proteksi Kebakaran gedung Laboratorium Teknik Mesin Fakultas Teknik Universitas Riau, Kelengkapan Tapak dengan bobot $25 \%$ dengan hasil penilaian $17.97 \%$. Sarana Penyelamatan dengan bobot $25 \%$ dengan hasil penilaian $18.25 \%$. Sistem Proteksi Aktif dengan bobot $24 \%$ dengan hasil penilaian $15 \%$. Sistem Proteksi Pasif dengan bobot $26 \%$ dengan hasil penilaian $21.28 \%$.

Penilaian kondisi keseluruhan sistem proteksi kebakaran Laboratorium Teknik Mesin Fakultas Teknik Universitas Riau yaitu sebesar 72.5\%. Menurut Pemeriksaan Keselamatan Kebakaran Bangunan Gedung tahun 2005 menunjukan bahwa kondisi sistem proteksi kebakaran pada bangunan Laboratorium Teknik Mesin Fakultas Teknik Universitas Riau dalam kondisi cukup. Dengan kondisi yang ada ini diharapkan sistem proteksi dapat berfungsi dengan baik saat dibutuhkan bila sewaktu-waktu terjadi bahaya kebakaran.

\section{DAFTAR PUSTAKA}
Badan Penelitian dan Pengembangan Pekerjaan Umum Departemen Pekerjaan Umum., 2005 Pemeriksaan Keselamatan Kebakaran Bangunan Gedung. Jakarta.

Pangesti, A.D.H., 2012, "Gambaran Tingkat Pengetahuan dan Aplikasi Kesiapan Bencana Pada Mahasiswa Fakultas Ilmu Keperawatan Universitas Indonesia”, Skripsi Sarjana, Program Studi Ilmu Keperawatan Fakultas Ilmu Keperawatan, Universitas Indonesia, Depok.

Peraturan Mentri Pekerjaan Umum No.20/PRT/M/2008., 2008, Pedoman Teknis Manajemen Proteksi Kebakaran di Perkotaan. Jakarta.

Peraturan Mentri Pekerjaan Umum No.20/PRT/M/2009., 2009, Pedoman Teknis Manajemen Proteksi Kebakaran di Perkotaan. Jakarta.

Riduan. 2013. Dasar-Dasar Statistik. Penerbit Alfabeta, Bandung.

Rizki, Rika Sri., Sara, Devi Ira., \& Gapy, Mansur., 2017, "Sistem Deteksi Kebakaran Pada Gedung Berbasis Programmabel Logic Controller (PLC)", Jurnal Online Teknik Elektro, Vol.2 No.3, 99-104.

Sugiyanto, D. and Anmar, E.R., 2018. Analisa Sistem Perpipaan Pompa Sentrifugal 1500 Gpm pada Mobil Pemadam Kebakaran. Jurnal Kajian Teknik Mesin, 3(2), pp.57-65.

Susetyo, F.B., 2016. Peningkatan Kondisi Area Bahan Laboratorium Produksi Teknik Mesin Fakultas Teknik Universitas Negeri Jakarta. 
Jurnal Kajian Teknik Mesin Vol 5 No 1 (Feb 2020) 22-28

Jurnal Kajian Teknik Mesin, 1(1), pp.1-8. 